\title{
O EXERCÍCIO DA LIDERANÇA SOB A ÓTICA DE ENFERMEIROS DE PRONTO SOCORRO
}

\author{
Daniele Araszewski ${ }^{1}$, Michele Bianca Bolzan², Juliana Helena Montezeli ${ }^{3}$, Aida Maris Peres ${ }^{4}$
}

\begin{abstract}
RESUMO: Estudo descritivo com abordagem qualitativa que objetivou identificar como enfermeiros de um pronto socorro percebem o exercício da liderança em sua prática profissional. Os dados foram coletados por meio de entrevistas semiestruturadas com nove enfermeiros de um hospital-escola de Curitiba - Paraná, de maio a julho de 2011. Após a transcrição das entrevistas, os dados foram submetidos à análise de conteúdo, que deu origem a três categorias. A primeira descreve o conceito de liderança na perspectiva dos enfermeiros; na segunda são abordadas as características da liderança a serem praticadas no pronto socorro e na terceira discorre-se sobre os atributos do enfermeiro-líder no cenário emergencial hospitalar. Conclui-se que a liderança é uma competência gerencial essencial para a prática do enfermeiro no setor de emergência e que, para sua efetiva mobilização, ele deve manter-se atualizado e fazer uso das habilidades de comunicação, negociação, autonomia, criatividade e valorização dos membros da equipe.
\end{abstract}

DESCRITORES: Enfermagem em emergência; Liderança; Pesquisa em administração de enfermagem.

\section{EL EJERCICIO DEL LIDERAZGO POR LA ÓPTICA DE ENFERMEROS DE HOSPITAL DE URGENCIA}

RESUMEN: Estudio descriptivo con abordaje cualitativo cuyo objetivo fue identificar cómo enfermeros de servicio de urgencia perciben el ejercicio del liderazgo en su práctica profesional. Los datos fueron obtenidos por medio de entrevistas semiestructuradas con nueve enfermeros de un hospital-escuela de Curitiba - Paraná, de mayo a julio de 2011. Después de la transcripción de las entrevistas, los datos fueron sometidos al análisis de contenido, que resultó en tres categorías. La primera describe el concepto de liderazgo en la perspectiva de los enfermeros; en la segunda son abordadas las características de liderazgo que serán practicadas en la emergencia y, en la tercera se discute acerca de los atributos del enfermero-líder en el ambiente del hospital de emergencia. Se concluye que el liderazgo es una competencia administrativa esencial para la práctica del enfermero en el sector de emergencia y que, para esa efectiva movilización, este debe mantenerse actualizado y utilizar la habilidades de comunicación, negociación, autonomía, creatividad y valoración de los miembros del equipo.

DESCRIPTORES: Enfermería en emergencia; Liderazgo; Investigación en administración de enfermería.

\section{THE EXERCISING OF LEADERSHIP IN THE VIEW OF EMERGENCY ROOM NURSES}

\begin{abstract}
This descriptive study with a qualitative approach aimed to identify how nurses from an Emergency Room perceive the exercising of leadership in their professional practice. The data were collected through semi-structured interviews with nine nurses from a teaching hospital in Curitiba in the State of Paraná, in May - July 2011. Following the interviews' transcription, the data were submitted to content analysis, which produced the three categories. The first describes the concept of leadership in the view of the nurses; the second addresses the leadership's characteristics to be practised in Emergency Room and the third discusses the attributes of the nurse leader in the hospital emergency setting. It is concluded that leadership is an essential management competency for the nurse's practice in the emergency department and that, for the nurse's effective mobilization, she must keep herself up-to-date and make use of the skills of communication, negotiation, autonomy, creativity, and valorization of the team members. DESCRIPTORS: Emergency nursing; Leadership; Research in nursing administration.
\end{abstract}

${ }^{1}$ Enfermeira. Hospital Universitário Cajuru. Curitiba-PR-Brasil

${ }^{2}$ Enfermeira. Marcelino Champagnat. Londrina-PR-Brasil

${ }^{3}$ Enfermeira. Mestre em Enfermagem. Professora da Universidade Estadual de Londrina. Londrina-PR-Brasil

${ }^{4}$ Enfermeira. Doutora em Enfermagem. Professora da Universidade Federal do Paraná. Curitiba-PR-Brasil 


\section{INTRODUÇÃO}

A enfermagem é caracterizada como uma profissão de múltiplas vertentes e cabe ao enfermeiro assumir o papel de líder nas suas diversas práticas como o cuidar, a educação em saúde, a pesquisa e a gerência ${ }^{(1)}$. A liderança é uma competência gerencial essencial para a prática profissional do enfermeiro da qual depende o sucesso de todas as esferas compositoras de seu processo de trabalho.

Salienta-se que, na atualidade, a exigência por uma assistência à saúde de qualidade da clientela que aporta nos diferentes serviços é cada vez maior, e o gerenciamento em enfermagem contribui sobremaneira neste contexto ${ }^{(2)}$. Diante disso, é fundamental que os enfermeiros estejam cônscios do modo como exercem liderança para que possam gerenciar, com eficácia, e proporcionar assistência de qualidade aos clientes. Com isto, a enfermagem poderá ser valorizada e respeitada pelas pessoas que buscam seus cuidados e também pela equipe de saúde ${ }^{(3)}$.

Ainda que a liderança possua diferentes abordagens, é unânime entre os estudiosos da área que ela se trata de uma prática de influenciar pessoas. Salienta-se, ainda, que hodiernamente, uma postura autocrática do líder na área da saúde não encontra eco nas exigências das instituições de saúde, apregoando-se a necessidade de uma prática linear de liderança, com a participação de todos os atores envolvidos neste processo(3).

A liderança do enfermeiro deve ser construída desde a sua formação acadêmica. Com base nas Diretrizes Curriculares Nacionais (DCN), a formação do enfermeiro tem como um dos seus vários objetivos o desenvolvimento para o exercício de habilidades e competências como: comunicação, liderança, tomada de decisão, educação permanente, administração e gerenciamento ${ }^{(4)}$.

Já na vida profissional do enfermeiro, a utilização da liderança é uma das preconizações de sua Lei do Exercício Profissional $^{(5)}$, pois, entre outras coisas, possibilita maior facilidade para coordenar a equipe, as ações gerenciais e também a assistência de enfermagem ${ }^{(6)}$.

Durante a atuação como enfermeiros e docentes em um Pronto-Socorro (PS), os autores observaram que tal ambiência requer postura diferenciada do enfermeiro e que a liderança por ele exercida demonstra peculiaridades exigidas pelas situações de emergência. Essas inquietações culminaram nesta investigação, que se norteia pelo seguinte objetivo: identificar como enfermeiros de um pronto-socorro percebem o exercício da liderança em sua prática profissional.
A pesquisa justifica-se pela possibilidade de seus construtos fornecerem subsídios para os profissionais que atuam em PS, ou em serviços de urgência e emergência, poderem reconhecer a importância da liderança na sua prática profissional, identificando que a liderança necessita ser desenvolvida e que faz parte das competências gerenciais do enfermeiro. Tendo em vista que se trata de um processo que influencia grupos para atingir um objetivo, por meio dela o enfermeiro pode coordenar as ações de sua equipe de maneira assertiva, prestando uma assistência de qualidade ao paciente que adentra neste setor.

\section{MÉTODO}

Pesquisa descritiva com abordagem qualitativa, feita no PS de um hospital escola filantrópico de Curitiba - Paraná, Brasil. Todos os enfermeiros do setor foram convidados a participar da pesquisa, sendo o critério de inclusão atuar exclusivamente neste cenário. Assim, dos 10 enfermeiros que compunham o quadro funcional do setor, nove deles participaram.

Os preceitos éticos obedeceramà Resolução 196/96 do Conselho Nacional de Saúde ${ }^{(7)}$ e a coleta de dados deu-se após aprovação do projeto pelo Comitê de Ética em Pesquisa da instituição hospitalar sob protocolo n. 3777/11.

A obtenção dos dados ocorreu de maio a julho de 2011, por meio de entrevistas semiestruturadas norteadas por um instrumento composto de quatro questões abertas: 1) O que você entende por liderança? 2) Qual o papel de um líder no trabalho? 3) Como você compreende a liderança do enfermeiro na prática profissional? 4) Quais os desafios em ser um enfermeiro líder?

As entrevistas foram feitas individualmente no próprio setor de trabalho, gravadas e com duração entre cinco e 15 minutos. As falas foram transcritas e tratadas pela Análise de Conteúdo ${ }^{(8)}$. Este tipo de análise ocorre em três etapas: a pré-análise (transcrição das falas gravadas dos participantes de forma a constituir o corpus do texto a ser trabalhado), a exploração do material (transformação dos dados brutos em núcleos de compreensão do texto) e o tratamento dos resultados (durante o qual são realizadas inferências e interpretação dos achados, com sustentação de literaturas abordando a temática e exemplificações utilizando falas dos participantes) ${ }^{(8)}$.

A partir categorias originadas, desenvolveram-se discussões pautadas na literatura para fundamentar as reflexões, as quais foram exemplificadas com falas codificadas como EE1 a EE9 (entrevista do enfermeiro 
um à entrevista do enfermeiro nove), com o intuito manter o anonimato dos participantes.

\section{RESULTADOS}

Emergiram as categorias: Conceito de liderança na perspectiva dos enfermeiros do PS; Características da liderança a serem praticadas no PS e Especificidades do enfermeiro-líder no PS.

\section{Conceito de liderança na perspectiva dos enfermei- ros do PS}

Os pesquisados enfatizaram alguns conceitos de liderança e o primeiro ponto abordado diz respeito ao líder como referência da equipe, conforme mostram os exemplos a seguir:

Liderar uma equipe é ser uma referência, dar exemplos bons e ser o exemplo. (EE2)

Se você não for a referência, a equipe não vai saber onde procurar ajuda para resolver os problemas. (EE7)

Outro ponto abordado foi o uso da liderança na condução da equipe e o gerenciamento no cumprimento de regras para coordenar as atividades cotidianas:

Liderança é você saber conduzir uma equipe em situação emergencial, em situações da prática e na vivência do dia a dia, [...] não só a equipe, mas as regras daquele ambiente também. (EE1)

\section{Características da liderança a serem aplicadas no PS}

O recorte a seguir ilustra a questão da forma compartilhada de liderar:

Eu acho que liderança se define como colaboração mútua. Você precisa estar lado a lado do seu funcionário e ele deve te ver como ponto chave, como uma pessoa que está ali para coordenar e colaborar com ele no desenvolvimento das atividades. (EE9)

Os enfermeiros destacaram a necessidade de legitimar a posição de líder por meio do conhecimento ao invés do autoritarismo:

O enfermeiro precisa liderar com segurança, liderar com conhecimento para que possa ter o respeito e o apoio da equipe, não só da equipe de enfermagem, mas da equipe multiprofissional que atua com ele dentro do PS. (EE4)

Se ele for só um enfermeiro autoritário, que tenta se impor, ele não vai conseguir. Ele tem que ter a autoridade perante a equipe multiprofissional pelo conhecimento, pelo respeito que ele conquista, e não querer simplesmente comandar. (EE3)

\section{Atributos do enfermeiro-líder no PS}

Os participantes destacaram o planejamento do atendimento emergencial com identificação de prioridades e o planejamento relacionado à organização do fluxo do setor, conforme as falas evidenciadas:

Saber liderar é essencial porque se não tiver liderança você não vai saber conduzir uma emergência. (EE1)

O líder é aquela pessoa que organiza a sua equipe, que dirige, que identifica as prioridades, o que é mais necessário numa determinada situação de emergência. (EE4)

O uso da liderança com vistas ao planejamento e organização da dinamicidade e fluxo do PS também foi mencionado pelos entrevistados, como mostram os seguintes recortes:

$O$ enfermeiro tem que ter agilidade, visão crítica e saber organizar as coisas de acordo com o momento em que se encontra o fluxo do pronto-socorro. (EE9)

Muita gente pensa que o PS é um setor muito bagunçado, mas existe um fluxo e uma organização. Então, todo mundo trabalha dentro da sua escala para poder proporcionar beneficio para todos. (EE2)

Outra particularidade do enfermeiro-líder no PS elencada foi a capacidade de negociação para na administração de conflitos:

O PS tem as suas especificidades por ser um setor muito dinâmico, onde passa muita gente [...] então, existem os conflitos entre alguns funcionários, entre membros da equipe multiprofissional e até com os usuários e familiares. Nestas situações, o enfermeiro precisa ter um jogo de cintura diferenciado para saber resolver a situação. (EE8) 
A rapidez na tomada de decisão e a comunicação foram citadas como elementos importantes no exercício da liderança no serviço de emergência:

O enfermeiro como líder no PS precisa ter rapidez na tomada de decisão e na avaliação do paciente; necessita saber se comunicar com outros serviços, ter habilidade para executar procedimentos em curto espaço de tempo [...]. Para isto, tenho que ter um conhecimento amplo de várias patologias, tanto clínicas quanto cirúrgicas. (EE6)

Outro ponto importante para liderar no PS, na ótica dos estudados, foi o relacionamento interpessoal como pilar de sustentação para conduzir o trabalho em equipe:

Eu tenho que saber trabalhar em equipe, respeitar o espaço do outro para conseguir a confiança deles, [...] tenho que ter um bom relacionamento com todos, que ser o ponto de apoio deles, a referência de todos aqui dentro. (EE2)

Na concepção dos enfermeiros, há a necessidade de valorizar os aspectos humanísticos dos liderados como evidenciado no depoimento a seguir:

É importante conduzir o grupo de modo que cumpram a missão da instituição, mas entendendo a equipe como um todo, num aspecto tanto profissional quanto holistico, respeitando a individualidade de cada membro e compartilhando as decisões com estes da forma mais humanizada possivel. (EE6)

\section{DISCUSSÃO}

Ao discorrer sobre o conceito de liderança, os enfermeiros fizeram menção a dois pontos principais: o líder como referência da equipe e também como o responsável por guiá-la para o cumprimento das regras que regem atividades do seu dia a dia, demonstrando afinidade com os achados da literatura.

Para ser a referência da equipe, o líder precisa influenciar as atitudes de seus liderados, assim, a liderança se caracteriza por um processo em que um indivíduo exerce influência sobre o outro ${ }^{(9)}$. Complementando, liderar significa influenciar pessoas, motivando-as a realizar as suas tarefas de modo a atingirem a excelência no trabalho ${ }^{(3)}$.

Sendo o enfermeiro o ponto de referência e de exemplo para equipe, o comportamento do líder gera um reflexo no desempenho do grupo de trabalho, pois este se espelha no modelo que percebe como necessário para suas práticas diárias ${ }^{(10)}$.

Algumas habilidades para liderança estão intimamente ligadas aos conceitos exarados pelos enfermeiros entrevistados que são: aquele que toma decisão, comunicador, avaliador, facilitador, que assume riscos, influenciador e modelo de conduta ${ }^{(11)}$.

Ainda em consonância com as falas, os enfermeiros devem se planejar para realizar todas as atividades diárias de cuidado aos pacientes, resolução de problemas dos funcionários, ações burocráticas exigidas pela instituição e ainda, terem tempo para os imprevistos ${ }^{(12)}$. Em um estudo recente quanto à definição de liderança, as enfermeiras a caracterizaram como direção, coordenação, organização e comando, sendo o líder responsável pela equipe e pela execução do trabalho, devendo manter o respeito e o domínio da equipe ${ }^{(13)}$.

A liderança trata da condução ou coordenação de grupos e é uma das competências gerenciais mais evidentes no processo de trabalho do enfermeiro, uma vez que legalmente é este profissional que coordena as ações da equipe composta por técnicos e auxiliares de enfermagem $^{(14)}$.

Como função gerencial do enfermeiro, a liderança colabora, entre outras coisas, para influenciar no cumprimento de normas e rotinas, na previsão e provisão de recursos materiais e ambientais ${ }^{(10)}$.

Quanto às características da liderança a serem desempenhadas no PS, os depoimentos se reportam à liderança compartilhada, o que coaduna com os estudos sobre a temática, pois, atualmente, a marca da liderança é fortalecer o grupo de trabalho de maneira a valorizar as competências individuais e diluir o poder na equipe para que cada membro possa reconhecer o propósito e o significado de seu trabalho(15).

Especificamente no PS, para o enfermeiro desenvolver sua prática profissional, sobretudo em setores onde o trabalho é dinâmico, as equipes precisam atuar de forma sincronizada em muitas situações em que atendimento deve ser rápido, pois o paciente encontra-se em estado crítico com risco de morte. Assim, este profissional necessita desenvolver algumas competências para lidar com esta contingência, salientando-se a liderança ${ }^{(16)}$. Aliado a isto, tal como mencionado pelos participantes do estudo, os principais atributos necessários para o exercício da liderança são: comunicação, autoconfiança e inteligência. E como estratégias para o alcance da liderança são necessários: educação, comunicação, conhecimento técnico-científico e corresponsabilidade ${ }^{(3)}$. 
Desse modo, a liderança na ambiência emergencial deve ser legitimada por meio do conhecimento e não fazendo uso de práticas autoritárias. Nesta perspectiva, os enfermeiros da unidade de emergência devem unir a fundamentação teórica à capacidade de liderança, ao trabalho, ao discernimento, à iniciativa, à habilidade de ensino, à maturidade e à estabilidade emocional ${ }^{(16)}$.

Quanto aos achados da terceira categoria-sobre os atributos do enfermeiro-líder no PS - os participantes do estudo mostram uma percepção condizente com a literatura. Isso foi possível observar tendo em vista que os profissionais destacaram o planejamento do atendimento emergencial com identificação de prioridades e o planejamento relacionado à organização do fluxo do setor.

Cabe ao enfermeiro de emergência, além de realizar outras atividades, o planejamento das ações no sentido de otimizar o tempo disponível, de coordenar a equipe para que esta se aproprie das tecnologias disponíveis e assim garanta um cuidado integral e organizado aos pacientes. Este profissional está constantemente estabelecendo prioridades no atendimento e dividindo seu tempo e sua atenção entre a monitorização dos pacientes mais graves e a realização de procedimentos técnicos. Destarte, a liderança constitui um instrumento que favorece o planejamento da assistência e a coordenação da equipe no concernente à distribuição das tarefas e da delegação ${ }^{(17)}$.

O procedimento técnico atrelado ao planejamento de ações colabora para garantir ao paciente o cuidado de que ele necessita. Ao planejar, o enfermeiro determina os objetivos a serem alcançados para promover assistência de enfermagem de forma a adequar-se às necessidades dos indivíduos ${ }^{(18)}$.

As características de um setor de emergência englobam a instabilidade do ritmo de trabalho, o imediatismo das ações e a grande procura por atendimento, que variam em diversidade e complexidade ${ }^{(17)}$. Assim, é fundamental que o enfermeiro faça uso da liderança para planejar e organizar esta dinamicidade e o fluxo, o qual é diferenciado neste setor, como citado pelos pesquisados.

De acordo com a Lei n. 7.498, de 25 de Junho de 1986, em seu artigo 11, é competência do enfermeiro chefiar o serviço e a unidade de enfermagem em instituição pública e privada; organizar e dirigir os serviços de enfermagem e suas atividades técnicas e auxiliares; planejar, organizar, coordenar, executar e avaliar os serviços de assistência de enfermagem ${ }^{(5)}$. Assim, é necessário que os enfermeiros desempenhem o papel de líder, uma vez que está diretamente envolvido com aná- lise crítica, identificação de problemas, tomada de decisões, planejamento e implementação de cuidados, alocação de outros profissionais da equipe de enfermagem e motivação dos profissionais da equipe de saúde ${ }^{(19)}$.

No PS, o grande fluxo de pacientes atendidos e a dinamicidade da rotina fazem com que a atuação deste profissional deva ser eficaz e eficiente. Sob esta ótica, trata-se de uma categoria essencial ao processo de trabalho em tal ambiência, não apenas ao realizar $o$ atendimento emergencial, mas ao atuar efetivamente no gerenciamento da unidade e do cuidado, levando, assim, à melhor organização para sanar as necessidades de cada paciente ${ }^{(20)}$.

Dito isto, ressalta-se a importância da capacidade de negociação para administração de conflitos. Estes são fenômenos esperados e que ocorrem naturalmente nas organizações. Para administrá-los é preciso que o enfermeiro tenha competência para negociação, podendo agir com os comportamentos de compromisso, competição, cooperação, amenização, evitamento ou colaboração. Portanto, a negociação requer habilidades de liderança. Os administradores preparados realizam essa negociação de modo adequado, estão aptos para trocas e para agir diante de múltiplas alternativas. Isto exige que o líder tenha autoconfiança e assuma riscos ${ }^{(11)}$.

Em consonância com os discursos, o exercício da liderança eficaz é fundamental para a condução da equipe de enfermagem, principalmente no setor de urgência e emergência, no qual a tomada de decisão deve ser ágil e precisa ${ }^{(16)}$. A condição de dinamicidade e a complexidade das atividades desenvolvidas no serviço de emergência requerem do enfermeiro competência diferenciada para a tomada de decisão, uma vez que o tempo é um fator determinante para a efetividade do cuidado prestado e manutenção da vida. $\mathrm{O}$ desenvolvimento das ações dos enfermeiros na emergência está intimamente ligado à competência clínica, desempenho, cuidado global e cientificidade no processo gerencial, já que o ambiente emergencial está vinculado a constantes episódios de crise, os quais inspiram decisões rápidas e precisas ${ }^{(20)}$.

As habilidades para tomada de decisão compõem-se do pensamento crítico sobre as situações com base em análise, julgamento das perspectivas de cada proposta de ação e seus desdobramentos, sendo que o raciocínio lógico/intuitivo e a avaliação permeiam esse processo ${ }^{(21)}$. Assim, cabe ao enfermeiro de PS utilizar-se de suas capacidades para que a tomada de decisão quanto a o quê e como fazer seja ágil e de forma adequada ao gerenciar a unidade e o cuidado ao paciente ${ }^{(20)}$.

No que se refere à comunicação, assim como cons 
tatado pelos pesquisados, esta é um elemento de suma importância no processo de liderar do enfermeiro, pois a maneira como se dá a transmissão de mensagens interferirá no resultado desejado ${ }^{(15)}$. É inquestionável que para assumir uma boa liderança o enfermeiro deve ter habilidades de comunicação, ela representa uma troca de informação e compreensão entre as pessoas, com objetivo de transmitir fatos, pensamentos e valores ${ }^{(1)}$. O líder pode influenciar escolhas por meio da comunicação e, assim, promover aos liderados que sejam o melhor que possam $\operatorname{ser}^{(19)}$.

Contudo, sem bom relacionamento interpessoal o processo comunicacional pode ser dificultado, como versaram os enfermeiros. Para favorecer a prática assistencial, e a consequente satisfação da clientela e instituição, a atuação do enfermeiro deve embasar-se nas relações interpessoais e no desenvolvimento de cada membro da equipe. Relacionando-se adequadamente, o líder consegue transferir e receber o conhecimento, organizar seu serviço e traçar metas e objetivos juntamente com sua equipe ${ }^{(14)}$.

Como complemento, o enfermeiro traz em sua essência o contato com o outro, tanto no exercício do cuidado como também gerindo equipes. Além disso, resolve conflitos e pratica a equidade na tomada de decisões. Para tal, norteia-se pela ética e lei do exercício profissional, orienta novas condutas, busca a participação da sua equipe na construção de planos e projetos, enfim serve de inspiração para que haja seguidores dispostos a trilhar seus caminhos. Assim, o enfermeiro será líder e não chefe e conseguirá trabalhar junto com os membros de sua equipe com plena satisfação profissional $^{(15)}$.

Distancia-se, portanto, de antigos paradigmas, segundo os quais a liderança era caracterizada pelo poder centralizador, no qual o relacionamento entre os membros da equipe acontecia sob uma relação de poder, por parte do até então considerado líder, e obediência por parte dos demais. No novo paradigma, o líder consiste naquela pessoa que, por meio do diálogo, motiva os colaboradores a trabalhar com entusiasmo na busca dos objetivos determinados pela equipe ${ }^{(19)}$.

Corroborando com estes pensamentos, como mencionado anteriormente e citado pelos participantes, observa-se atualmente a existência de um novo modelo de liderança: descentralização do processo decisório, ênfase nas relações interpessoais, comunicação, disposição para assumir riscos, motivação e valorização do indivíduo. Isto porque os moldes da administração clássica de receber e executar ordens parecem não mais atender às necessidades da enfermagem, a qual busca uma administração flexível ${ }^{(22)}$.

Assim, o enfermeiro-líder passou a ser visto como um profissional que almeja a transformação e o bemestar dos seus liderados ${ }^{(1)}$. E a liderança passa a ser um fator para que o envolvimento, satisfação e motivação transformem o trabalho dos membros da equipe de enfermagem em atividade prazerosa ${ }^{(20)}$.

\section{CONSIDERAÇÕES FINAIS}

Observa-se que o exercício da liderança faz-se cada vez mais necessário para a condução de uma equipe eficiente, sendo esta uma habilidade que envolve a relação entre o enfermeiro e os funcionários, estimulando a colaboração da equipe para um atendimento emergencial qualificado e visando o melhor para os pacientes que adentram neste setor.

No período de realização deste trabalho, observouse que alguns enfermeiros tiveram dificuldade em definir liderança, bem como algumas características e especificidades que são utilizadas em suas atividades diárias. De acordo com as entrevistas realizadas, destacou-se que o enfermeiro líder é uma referência para a sua equipe. Outras questões pontuadas foram que o enfermeiro deve ter competência para a tomada de decisão, capacidade de comunicação, deve saber administrar os conflitos e valorizar seus colaboradores bem como suas atividades.

É imprescindível que dentro de um setor de emergência estabeleça-se a relação entre líder e liderados, sendo realizado um gerenciamento que vise o cuidado necessário ao paciente, um trabalho produtivo e um convívio entre colaboradores de maneira que favoreça a prática assistencial e administrativa do Pronto-socorro. Percebe-se que a prática do enfermeiro de emergência depende muito da sua competência de gerenciamento e para tal, é importante que ele mantenha-se atualizado e faça uso de suas capacidades de comunicação, negociação, autonomia, criatividade e conhecimento.

\section{REFERÊNCIAS}

1. Nascimento CD, Fonseca ISS, Moura SB, Servo MLS. O agir do enfermeiro no exercício da liderança em Enfermagem: dificuldades da prática. Rev enferm UFPE on line. [Internet] 2008;2(4) [acesso em 18 jun 2011]. Disponível: http://www.ufpe.br/ revistaenfermagem/index.php/enfermagem/article/ view/165/204

2. Montezeli JH, Peres AM. Competência gerencial do 
enfermeiro: conhecimento publicado em periódicos brasileiros. Cogitare enferm. 2009;14(3):553-8.

3. Vilela PF, Souza AC. Liderança: um desafio para o enfermeiro recém-formado. Rev. Enferm. UERJ. 2010;18(4):87-90.

4. Ministério da Educação (BR). Conselho Nacional de Educação. Diretrizes Curriculares Nacionais do Curso de Graduação em Enfermagem. Resolução n. 3, de 7 de novembro de 2001. Brasília; 2001.

5. Brasil. Lei n. 7.498, de 25 de junho de 1986. Dispõe sobre a Regulamentação do Exercício da Enfermagem e dá outras providências. Diário Oficial da República Federativa do Brasil, Brasília, 26 jun. 1986. Seção 1:1.

6. Amestoy SC, Trindade LL, Waterkemper R, Heidman ITS, Boehs AE, Backer VMS. Liderança dialógica nas instituições hospitalares. Rev. bras. enferm. 2010;63(5):844-7.

7. Ministério da Saúde(BR). Conselho Nacional de Saúde. Diretrizes e normas regulamentadoras de pesquisa envolvendo seres humanos. Resolução n. 196, de 10 de outubro de 1996. Brasília; 1996.

8. Bardin L. Análise de conteúdo. Lisboa: Edições 70; 2011.

9. Chaves EHB, Moura GSS. O estilo de liderança de enfermeiros: relato de experiência. Rev. Gaúcha Enferm. 2003;24(3):355-64.

10. Santos I, Castro CB. Estilos e dimensões da liderança: iniciativa e investigação no cotidiano do trabalho de enfermagem hospitalar. Texto Contexto Enferm. 2008;17(4):734-42.

11. Marquis BL, Houston CJ. Administração e liderança em enfermagem. $6^{\mathrm{a}}$ ed. Porto Alegre: Artmed; 2010.

12. Mello MC, Fugulin MFT, Gaidzinski RR. O tempo no processo de trabalho de saúde: uma abordagem sociológica. Acta Paul. Enferm. 2007;20(1):87-90.

13. Trindade LL, Amestoy SC, Muniz LA, Biolchi T, Pires DEP, Backes VMS. Influência dos estilos de liderança do enfermeiro nas relações interpessoais da equipe de enfermagem. Enfermería Global. 2011;10(2) [acesso em 18 jun 2011]. Disponível: http://revistas.um.es/eglobal/ article/view/122781/115381

14. Ribeiro M, Santos SL, Meira TGBM. Refletindo sobre liderançaemenfermagem. Esc. AnnaNery.2006;10(1):109-15.

15. Balsanelli AP, Cunha ICK. Liderança no contexto da enfermagem. Rev Esc Enferm USP. 2006;40(1):117-22.

16. Wehbe G, Galvão MC. Aplicação da Liderança Situacional em enfermagem de emergência. Rev. bras. enferm. 2005;58(1):33-8.

17. Santos JLG. A dimensão gerencial do trabalho do enfermeiro em um serviço hospitalar de emergência. [dissertação]. Porto Alegre (RS): Universidade Federal do Rio Grande do Sul; 2010.

18. Hausmann M, Peduzzi M. Articulações entre as dimensões gerencial e assistencial do processo de trabalho do enfermeiro. Texto Contexto Enferm. 2009;18(2):258-65.

19. Souza LB, Barroso MGT. Reflexões sobre o cuidado como essência da liderança em enfermagem. Esc. Anna Nery. 2009;13(1):181-7.

20. Montezeli JH. O trabalho do enfermeiro no prontosocorro: uma análise na perspectiva das competências gerenciais [dissertação]. Curitiba (PR): Universidade Federal do Paraná; 2009.

21. Peres AM, Ciampone HMT. Gerência e competências gerais do enfermeiro. Texto Contexto Enferm. 2006;15(3):492-9.

22. Jadielma CS, Rozendo CA, Brito FMM, Costa TJG. A percepção do formando de enfermagem sobre a função gerencial do enfermeiro. Rev. Eletr. Enf. [Internet]. 2012;14(2) [acesso em 25 mar 2012]. Disponível: http:// www.fen.ufg.br/revista/v14/n2/v14n2a09.htm. 